\title{
Osmolal balance after open intracardiac operations in children
}

\author{
PHILIP B. DEVERALL, DAVID C. MUSS, \\ FERGUS J. MACARTNEY, and JOHN D. SETTLE \\ Department of Surgery, Leeds Regional Cardiothoracic Centre, Killingbeck Hospital, Leeds LS14 6UQ
}

\begin{abstract}
Deverall, P. B., Muss, D. C., Macartney, F. J., and Settle, J. D. (1973). Thorax, 28, 756761. Osmolal balance after open intracardiac operations in children. Changes in plasma osmolality, urine osmolality, urine volume, total osmolal output, and free osmolal output have been studied in children between 2 and 10 years of age. All underwent elective open intracardiac operations.

Plasma hypo-osmolality develops after operation, and this was not influenced by altering the osmolal concentration of the prime in the extracorporeal system nor was it affected by severe water restriction in the immediate postoperative period. During the first $\mathbf{4 8}$ hours a water diuresis was not seen even in the presence of marked plasma hypo-osmolality.

Urine volume, urine osmolality, and solute concentration in the kidney are affected by both the perfusate prime and postoperative fluid regime. As the total osmolal output was the same in all study groups, there was an inverse relation between urine volume and urine osmolality.

The data obtained show no evidence of postoperative renal dysfunction. Free osmolal output, a measure of solute and water excretion, showed a normal renal response to a solute load but an abnormal response to a water load.

The data support the use of moderate haemodilution in the perfusate prime, the precise osmolal concentration not being of major importance. Postoperatively a regime of moderate fluid restriction is supported.
\end{abstract}

Changes in body composition in surgical patients have been recognized and studied since the pioneering work of Cuthbertson, reported in 1932. Moore and Ball (1952) have defined changes in body water and electrolytes. Recently, body compositional changes have been described in patients undergoing open intracardiac operations (Pacifico, Digerness, and Kirklin, 1970 ; Moffitt, Rosevear, and McGoon, 1970 ; Breckenridge, Digerness, and Kirklin, 1970 ; Breckenridge, Deverall, Kirklin, and Digerness, 1972). Significant increases in extracellular water and total exchangeable sodium occur early after operation together with a reduction in total exchangeable potassium.

Plasma hypo-osmolality has been recorded in the postoperative period, and a low serum concentration is frequently observed. As low plasma osmolalities have been described in association with cerebral dysfunction, it seemed important to establish the frequency, timing, and extent of osmolar

Requests for reprints to P. B. Deverall, F.R.C.S., Killingbeck Hospital, Leeds LS14 6UO change after open intracardiac operations.

Such operations are unique in that the body is perfused during the period of extracorporeal circulation with a mixture of the patient's blood and the contents of the extracorporeal system. This system may contain fluids of abnormal osmolar concentration and thus the osmoregulatory centres of the patient might be perfused with blood of significantly abnormal osmolar composition. It seemed important to inquire whether such an occurrence affected the observed changes in body composition.

Postoperative parenteral fluids, in terms of composition and volume, have been determined by the body compositional changes described by Pacifico et al. (1970), and 5\% dextrose with added potassium is the basis of our management programme after open intracardiac operations. Since this fluid is hypo-osmolar it seemed important to assess the effect of varying the volume of parenteral fluids on observed changes in osmolar balance.

To try to answer these questions a study of three 
groups of children undergoing elective open intracardiac operations was undertaken. Two different extracorporeal perfusates were used, one moderately hyperosmolar and one iso-osmolar. Two different systems of parenteral fluid replacement were used. These variables were combined in the three study groups.

\section{MATERIAL}

All the children in the three study groups were between 2 and 10 years of age and were undergoing elective open intracardiac operations. No child had cardiac failure before operation and none was receiving digoxin or diuretics. Only children having an uncomplicated operative and postoperative course have been analysed. The three groups were as follows:

GROUP 1 The extracorporeal system was primed with a haemodilution mixture of acid citrate dextrose blood (ACD) and Ringer's lactate with added sodium bicarbonate (Table). The blood, less than 24 hours old, contained the disodium citrate salt. After operation ACD blood was used as necessary. Parenteral fluid was $5 \%$ dextrose in water $-500 \mathrm{ml} / \mathrm{m}^{2}$ body surface area between the end of operation and 09.00 hours on the first postoperative day (day 0 ) and $750 \mathrm{ml} 5 \%$ dextrose in water in the next 24 hours (day 1). Oral fluids were started as sips only late on day 1 . Ten milliequivalents per square metre of potassium chloride were given on day 0 and $20 \mathrm{mEq} / \mathrm{m}^{2}$ on day 1 .

T A B L E

PERFUSATE COMPOSITION: GROUPS 1 AND 3

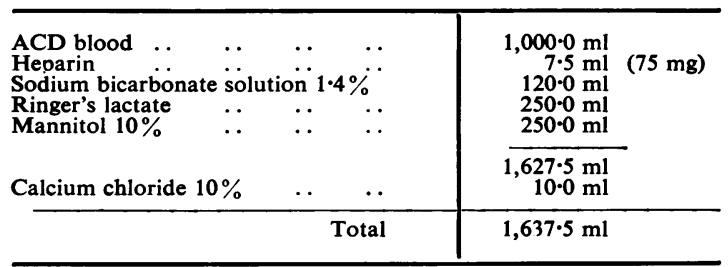

GROUP 2 The extracorporeal system was primed with fresh whole heparinized blood with no additions. Postoperatively ACD blood was used together with the identical fluid programme described for group 1.

GROUP 3 The extracorporeal system was primed as for group 1, but an attempt was made to reduce to the minimum additional fluids during operation. Postoperatively parenteral fluid was restricted to $100 \mathrm{ml}$ $5 \%$ dextrose in water per square metre on day 0 . Oral fluids were begun on day 1 according to thirst demands. The potassium amount was as previously stated.

As far as possible all other aspects of operative and postoperative management were standardized. The Bentley Temptrol oxygenator (Q110) was used at a flow rate of $2.41 / \mathrm{m}^{2}$ per minute together with mild total body hypothermia to $33^{\circ} \mathrm{C}$. Left and right atrial pressures were monitored and infusion of blood and/or plasma was determined on the basis of achieving and maintaining atrial filling pressures associated with adequate cardiac performance. Early after operation ventilation was assisted with a volume cycled ventilator (Engstrom), spontaneous ventilation being established in all patients in the first 18 hours after operation. Continuous positive airway pressure spontaneous ventilation was not used in any of these patients.

\section{METHODS}

Plasma and urine osmolality were measured before, during, and for a 48-hour period after operation by the depression of freezing point technique (Settle, 1971').

All urine passed after the bladder had been emptied before operation was collected and appropriate samples were taken for analysis.

The perfusate composition, additions to the perfusate circuit during operation, and postoperative fluid administration were rigidly controlled. No diuretic was given to any patient at any time during the study.

$\frac{\text { Free osmolal output }=\text { Vol }(1 / \mathrm{hr}) \times\left(\mathrm{Uo}_{\mathrm{sm}}-\mathrm{Plo}_{\mathrm{sm}}\right)}{\text { Body wt }(\mathrm{kg})}$

A positive value implies that a concentrated urine with respect to plasma is passed, whereas a negative value would imply a water diuresis.

Urine volume and total osmolar output were corrected to body surface area.

\section{RESULTS}

PLASMA OSMOLALITY Plasma osmolality before, during, and after operation in groups 1,2 , and 3 is shown in Figures 1, 2, and 3. There was no significant difference between plasma osmolalities in the three groups before operation, the osmolalities being in the normal range $\left(285 \pm 5 \mathrm{~m}_{\mathrm{Osm}} / \mathrm{kg}\right)$. Patients in group 1 (Ringer's lactate-ACD prime with 'free fluids') had a significantly higher plasma osmolality than patients in group 2 (whole blood'free fluids') during and for 8 hours after operation $(P<0.05$ at 0,4 , and 8 hours). Group 1 patients also had a higher early postoperative plasma osmolality than the restricted fluid group 3 patients $(P<0.02$ at 4 hours and $P<0001$ at 8 and 12 hours). There were no significant differences between groups 2 and 3 patients during and early after operation. After 12 hours there was no significant difference in the plasma osmolalities of all three groups-all patients demonstrating a trend to hypo-osmolality -this achieving significance after 28 hours. Thirst was a common symptom in patients in all three groups.

URINE OSMOLALITY Urine osmolality in milliosmoles per litre of urine are shown for the three

1 Advanced Osmometer-Advanced Instruments Inc., Massachusetts, U.S.A. 


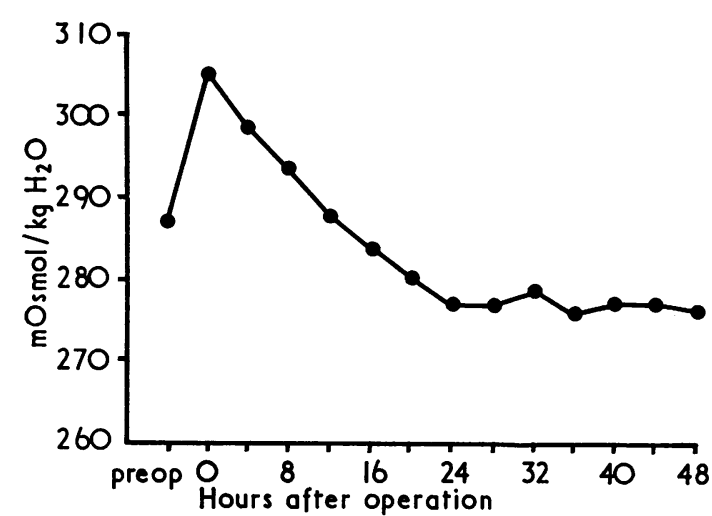

FIG. 1. Plasma osmolality in group 1.

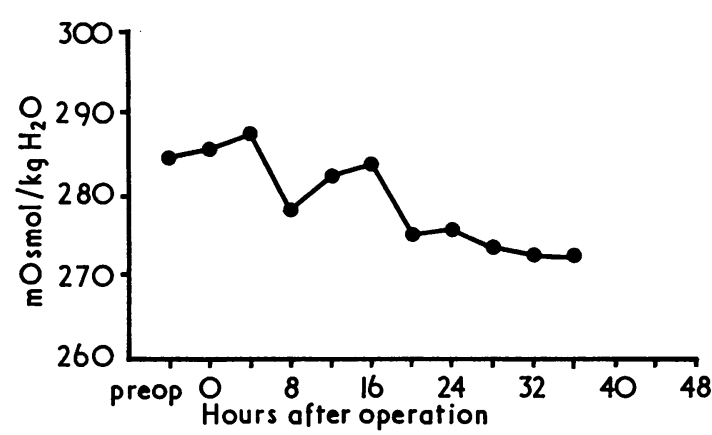

FIG. 2. Plasma osmolality in group 2.

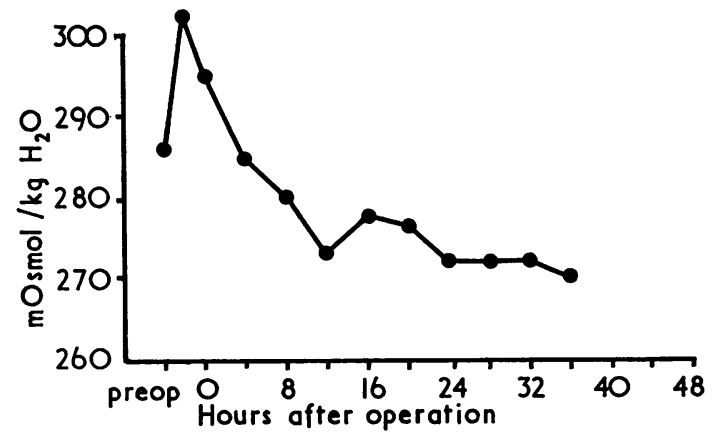

FIG. 3. Plasma osmolality in group 3.

groups in Figures 4, 5, and 6. Lower urine osmolalities were recorded in group 1 patients than in patients in the other groups. Comparing group 1 and group 2 patients, the urine osmolality was significantly lower in group 1 from 4 to 24 hours after perfusion $(P<0.01)$. Comparing group 1 and group 3 patients, significantly lower urine osmolalities were present in group 1 at $12(\mathrm{P}<0.05)$ and
$16(\mathrm{P}<0.02)$ hours. Patients in group 2 (whole blood perfusate) also were significantly different from the restricted fluid intake group in that urine osmolality was higher in group 2 at 8 hours $(P<0.02), 20$ hours $(P<0.05), 24$ hours $(P<0.05)$, and 32 hours $(P<0.01)$. In all groups the overall trend was an increasing urine osmolality during the postoperative period.

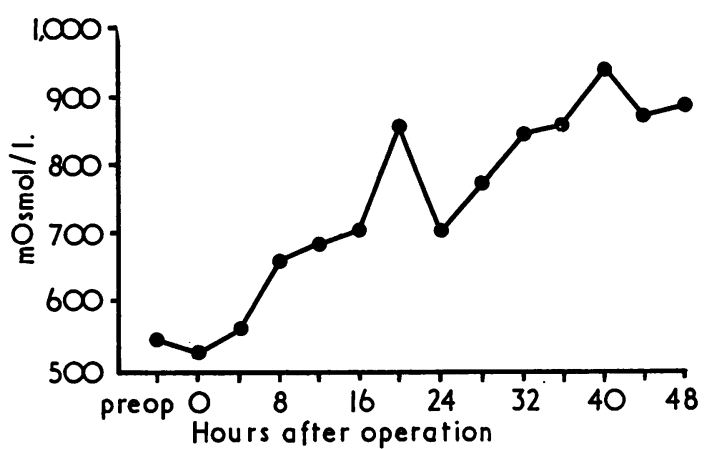

FIG. 4. Urine osmolality in group 1.

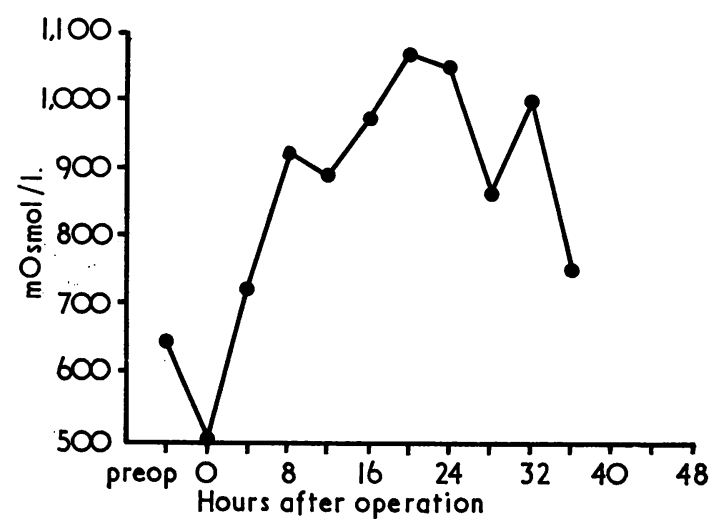

FIG. 5. Urine osmolality in group 2.

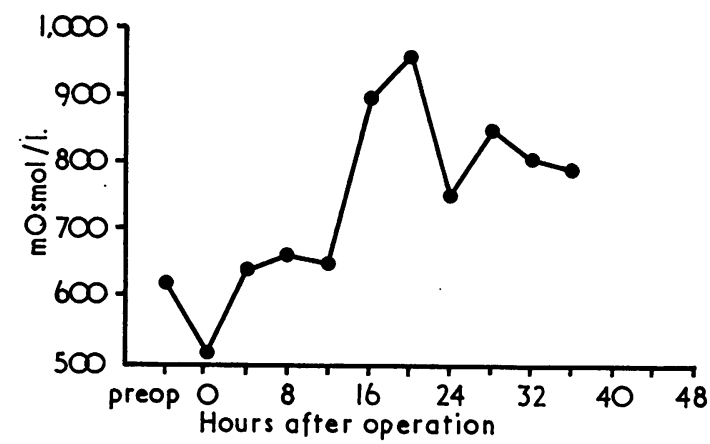

FIG. 6. Urine osmolality in group 3. 
URINE VOLUME Urine volumes, corrected to body surface area, are shown in Figures 7, 8, and 9. There were considerable variations between different individuals in each group but, when analysed statistically, there were few differences between the three groups. Group 1 patients had a higher urinary output in the latter part of the operation and immediately afterwards, but subsequently there was no significant difference between groups 1 and 2 or 3 up to 24 hours. At this time

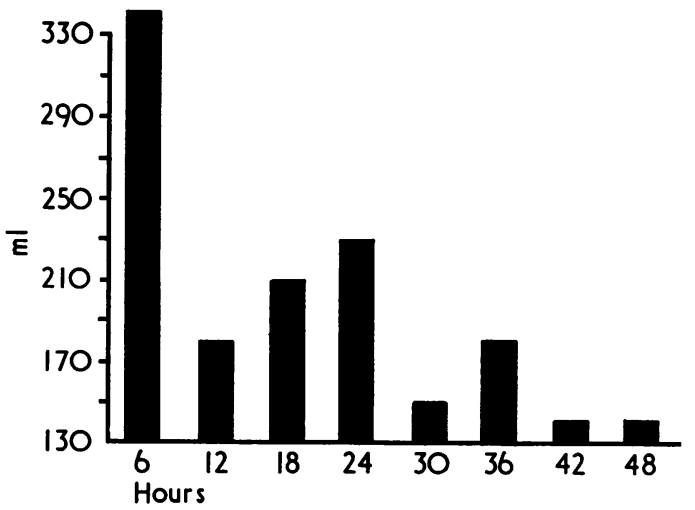

FIG. 7. Urine volume per square metre in group 1.

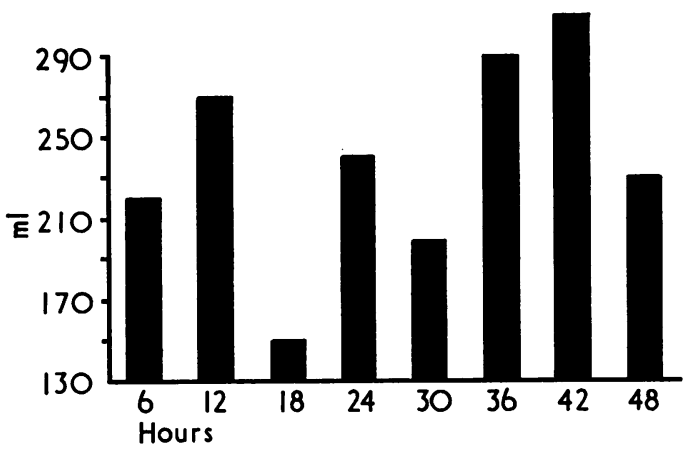

FIG. 8. Urine volume per square metre in group 2.

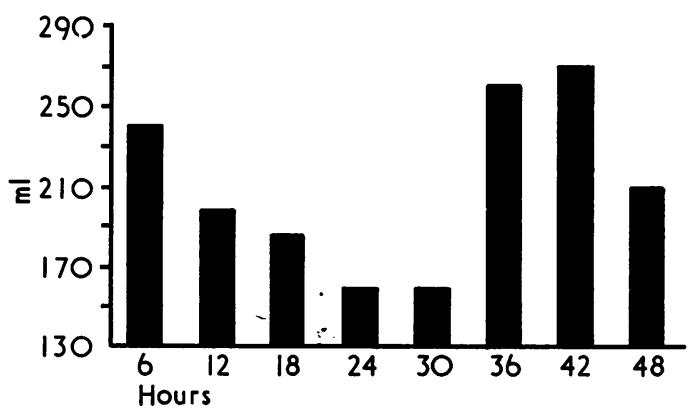

FIG. 9. Urine volume per square metre in group 3. there was a lower urinary output in the restricted fluid group 3 as compared to group $1(P<0.02)$. Groups 2 and 3 were similar throughout. In the second 24 hours the total urinary volume of groups 1 and 2 were similar though the pattern of urinary volume flow was different, the whole blood group 2 having a higher output at 42 hours $(\mathrm{P}<0.02)$.

FREE OSMOLAL OUTPUT Calculated free osmolal output, which is an expression of the osmolal concentrating function of the kidney, was calculated for each group on the basis of a sample at 6-hourly intervals. The results were similar in all groups in that free osmolal output remained in the normal positive range of +0.2 to $+2.0 \mathrm{mOsm} / \mathrm{kg}$ per hour. The positive value results from urine osmolality exceeding plasma osmolality at all phases of the study. A water diuresis or negative free osmolal output did not occur during the 48-hour study period even in those individual patients with the most marked degree of plasma hypo-osmolality, that is, less than $260 \mathrm{mOsm} / \mathrm{kg}$.

TOTAL OSMOLAL OUTPUT The total osmolal output corrected to body surface area was not significantly different comparing the three groups. This similarity held true over the whole period of the study and over each 6-hour period between the end of operation and 36 hours.

\section{DISCUSSION}

Changes in water balance and plasma and urine osmolality are recognized after various forms of stress including operative procedures. Hayes $e t$ al. (1959) showed that a procedure such as closure of a colostomy would be accompanied by antidiuresis and increased urinary osmolality over a period of three days. Moore and Ball (1952) showed that after major surgery the changes persisted for a longer period-often over five days. The original work of Verney (1947) suggested that the changes might be caused by the release of antidiuretic hormone, this consequent upon relatively minor changes in blood osmolar concentration as detected by the osmoregulators in the central nervous system.

Open intracardiac operations involving perfusion are unique in that the circulation is maintained by a perfusate consisting of the patient's blood mixed with the contents of the extracorporeal system. Changes in plasma osmolality after perfusion have been recorded by various workers. Sturtz, Kirklin, Burke, and Power (1957) descri- 
bed an increase in serum water concentration expressed as millilitres per milliosmole, and subsequent studies of Moffitt et al. (1970) described a fall in plasma osmolality in the first 48 hours after operation. Tsuchida et al. (1968) showed minimal changes in plasma osmolality after perfusion procedures in children, more marked changes being observed after non-perfusion procedures. Das, Eraklis, and Jones (1969) found that a reduction in plasma osmolality occurred with iso-osmolar perfusates but not with hyperosmolar perfusates. Moffitt, Molnar, and McGoon (1971) reported a significant difference in osmolar concentration in a group of patients surviving after aortic valve replacement compared with a group of patients dying with low cardiac output after valve replacement. In the latter patients the hypo-osmolar trend was not seen. Indeed in the preterminal phase plasma hyperosmolality was noted.

As previously emphasized, all patients analysed in this study had a relatively uneventful postoperative course.

A variety of perfusates were used by the various workers and many of the patients had acquired heart disease with undefined preoperative body compositional changes (Pacifico et al., 1970). We have studied children not in heart failure, and have attempted to define changes in plasma osmolality, urine osmolality, and renal solute/water excretion and to assess the effect of changes in perfusate composition and postoperative fluid management on these changes.

These studies confirm that plasma hypo-osmolality occurs postoperatively and that the hypoosmolar trend is not influenced by the osmolar concentration of the blood perfusate mixture, at least with the perfusates studied. This accords with the findings of Moffitt and colleagues using a more hyperosmolar perfusate in which ACD blood was diluted with $5 \%$ dextrose in $0.45 \%$ saline. During the hypo-osmolar period in these studies, that is, up to 48 hours postoperatively, a urine concentrated with respect to plasma is passed.

Hyponatraemia at this stage does therefore appear to be dilutional in type. Total exchangeable sodium is increased at this stage (Pacifico et al., 1970 ; Breckenridge et al., 1970) but clearly there is water retention over and above that which would accompany sodium retention. The results in group 3 patients clearly show that severe restriction of water intake postoperatively does not influence this situation. Indeed, as the total osmolar output is similar, the effect is merely to cause a reduction in the volume of urine which is significantly more concentrated. This study does show, at least in this group of well children, that renal concentrating mechanisms are unimpaired in this post-perfusion period. The body responds normally to a solute load whereas there is an 'abnormal' response to a water load. This may be due to antidiuretic hormone but, if this is so, then it is surprising that there is no difference in the osmolar trends in children in whom hyperosmolar and iso-osmolar perfusates were used. It is possible that non-pulsatile blood flow during perfusion fails adequately to perfuse the capillaries of the osmoregulatory centres. This seems unlikely since hyperosmolality extends into the immediate postperfusion period when a pulsatile circulation has been restored.

What recommendations can be made regarding perfusate composition and parenteral fluid management as a result of these studies?

A high urinary volume output seems desirable postoperatively. Free haemoglobin in the plasma following the trauma of extracorporeal circulation is better excreted by a high flow of urine. The osmolal load resulting from the perfusate and as part of the overall postoperative metabolic response is excreted but the degree of urinary concentration is inversely related to the total urinary volume. It thus seems correct to use a dilutional perfusate rather than whole blood.

Schuster, Kakvan, Vawter, and Narter (1964) and Glenn, Stansel, Hume, and Nakamura (1964) concluded that renal performance is probably superior after the use of a dilution perfusate rather than whole blood. We have no data which would confirm this.

The results of the severely restricted fluid intake group show that severe fluid restriction does not reduce the hypo-osmolality trend. Conversely, we cannot say that excessive water administration would accentuate the degree of hypo-osmolality. However, previous experience suggests that a syndrome of water intoxication can occur in the postoperative cardiac patient. We did not feel justified in subjecting any patient to a water load to assess this. Breckenridge et al. (1972), studying potassium metabolism after open intracardiac operations, found that the administration of varying amounts of potassium did not influence the state of potassium balance. The inference may be that the metabolic response to trauma is a fundamental one, of uncertain cause, and not susceptible to modification by variations in water and/or electrolyte intake.

Our policy regarding parenteral fluid has been to follow the recommendations of Sturtz et al. (1957). These workers based their formula of 
$500 \mathrm{ml} / \mathrm{m}^{2}$ on day 0 and $750 \mathrm{ml} / \mathrm{m}^{2}$ on days 1 and 2 on measured average obligatory water loss. Roth, Lax, and Maloney (1969), Breckenridge et al. (1970), Pacifico et al. (1970), and Cohn, Angell, and Shumway (1971) have recorded significant increases in total exchangeable sodium and extracellular water postoperatively. These findings support a policy of using sodium-free parenteral fluids at this time. However, we do not know that sodium retention would be increased by giving further sodium.

Das et al. (1969) recommended vigorous postoperative fluid replacement and Tsuchida et al. (1968) suggested an intake of $1,100 \mathrm{ml} / \mathrm{m}^{2}$ on day 0 and $1,400 \mathrm{ml} / \mathrm{m}^{2}$ on day 1 . We have no evidence that such a policy would be beneficial.

In conclusion, therefore, these results support the policy of moderate fluid restriction after haemodilution perfusion. As previously observed by Sturtz et al. (1957), thirst as a symptom is not synonymous with plasma hyperosmolality. Almost all of our patients complained of thirst, even those with marked plasma hypo-osmolality.

Judged on the basis of the free osmolal output (Settle, 1971), renal concentrating mechanisms were normal in this series of children and there was no evidence of renal dysfunction.

Full details of the data may be obtained from P. B. D.

\section{REFERENCES}

Breckenridge, I. M., Deverall, P. B., Kirklin, J. W., and Digerness, S. B. (1972). Potassium intake and balance after open intracardiac operations. Journal of Thoracic and Cardiovascular Surgery, 63, 305.

—, Digerness, S. B., and Kirklin, J. W. (1970). Increased extracellular fluid after open intracardiac operation. Surgery, Gynaecology and Obstetrics, 131, 53.

Cohn, L. H., Angell, W. W., and Shumway, N. E. (1971). Body fluid shifts after cardiopulmonary bypass. Journal of Thoracic and Cardiovascular Surgery, 62, 423.
Cuthbertson, D. P. (1932). Observations on the disturbance of metabolism produced by injury to the limbs. Quarterly Journal of Medicine, 25, 233.

Das, J. B., Eraklis, A. J., and Jones, J. E. (1969). Water and solute excretion following cardiopulmonary bypass with hemodilution. Journal of Thoracic and Cardiovascular Surgery, 58, 789.

Glenn, W. W. L., Stansel, H. C. Jr., Hume, M., and Nakamura, K. (1964). Clinical experience with prolonged cardiopulmonary bypass. Circulation, 29, Supplement 1 , p. 54.

Hayes, M. A., Byrnes, W. P., Goldenberg, I. S., Greene, N. M., and Tuthill, E. (1959). Water and electrolyte exchanges during operation and convalescence. Surgery, 46, 123.

Moffitt, E. A., Molnar, G. D., and McGoon, D. C. (1971). Myocardial and body metabolism in fatal cardiogenic shock after valvular replacement. Circulation, 44, 237.

- , Rosevear, J. W., and McGoon, D. C. (1970). Myocardial metabolism in children having open-heart surgery. Journal of the American Medical Association, 211, 1518.

Moore, F. D., and Ball, M. R. (1952). The Metabolic Response to Surgery. Thomas, Springfield, Illinois.

Pacifico, A. D., Digerness, S., and Kirklin, J. W. (1970). Acute alterations of body composition after open intracardiac operations. Circulation, 41, 331.

Roth, E., Lax, L. C., and Maloney, J. V. (1969). Ringer's lactate solution and extracellular fluid volume in the surgical patient. Annals of Surgery, 169, 149.

Schuster, S. R., Kakvan, M., Vawter, G. F., and Narter, N. (1964). An experimental study of the effect of mannitol during cardiopulmonary bypass. Circulation, 29, Supplement 1, p. 72.

Settle, J. A. D. (1971). Urine output following severe burns. M. Phil. thesis, University of Leeds.

Sturtz, G. S., Kirklin, J. W., Burke, E. C., and Power, M. H. (1957). Water metabolism after cardiac operations involving a Gibbon-type-pump-oxygenator. Circulation, $16,988$.

Tsuchida, Y., Nakajo, T., Hanawa, M., Sawaguchi, S., Ishida, M., and Saigusa, M. (1968). Parenteral fluid therapy following cardiac surgery in childhood. Japanese Heart Journal, 9, 520.

Verney, E. B. (1947). The antidiuretic hormone and the factors which determine its release. Proceedings of the Royal Society, Series B, 135, 25. 